\title{
Reciprocity in Quarantine: Observations from Wuhan's COVID-19 Digital Landscapes
}

\author{
Yanping $\mathrm{Ni}^{1}$ (D) $\cdot$ Morris Fabbri ${ }^{2}$ (I) $\cdot{\text { Chi } \text { Zhang }^{3} \text { (I) } \cdot \text { Kearsley A. Stewart }}^{4}$ (I)
}

Received: 10 July 2020 / Revised: 26 September 2020 / Accepted: 8 October 2020 / Published online: 20 November 2020

(C) National University of Singapore and Springer Nature Singapore Pte Ltd. 2020

\begin{abstract}
The 2003 SARS pandemic heralded the return of quarantine as a vital part of twenty-first century public health practice. Over the last two decades, MERS, Ebola, and other emerging infectious diseases each posed unique challenges for applying quarantine ethics lessons learned from the 2003 SARS-CoV-1 outbreak. In an increasingly interdependent and connected global world, the use of quarantine to contain the spread of SARS-CoV-2, or COVID-19, similarly poses new and unexpected ethical challenges. In this essay, we look beyond standard debates about the ethics of quarantine and state power to explore a key quarantine principle, Reciprocity, and how it is being negotiated by healthcare workers, volunteers, and citizens in the context of the Wuhan, China, quarantine. We analyze Reciprocity through the lens of two Wuhan case studies: (1) healthcare workers, particularly nurses, who are simultaneously essential workers and quarantined citizens, asked by their hospital administration to shave their heads because adequate PPE was not available, and (2) citizen-to-citizen mutual aid societies attempting to fill gaps in essential supplies left unfilled by the state. We analyze social media and video-blogs from Wuhan, on the platforms of Douyin and Sina Weibo, to understand how people define and respond to ethical and legal obligations in the wake of COVID-19. It is no surprise that quarantine principles from the 2003 SARS outbreak are inadequate for COVID-19 and that both infectious disease outbreak responses and ethics must adapt to the virtual age. We offer ideas to strengthen and clarify Reciprocal obligations for the state, hospital administrators, and citizens as the globe prepares for the next wave of COVID-19 circulating now.
\end{abstract}

Keywords COVID-19·SARS-CoV-2 $\cdot$ Quarantine $\cdot$ Reciprocity $\cdot$ Wuhan $\cdot$ China $\cdot$ Social media $\cdot$ Mutual aid $\cdot$ Douyin $\cdot$ TikTok

Kearsley A. Stewart

k.stewart@duke.edu

Asian/Pacific Studies Institute, Duke University, Durham, NC, USA

2 Science \& Society, Duke University, Durham, NC, USA

3 Duke Global Health Institute, Duke University, Durham, NC, USA

4 Global Health and Cultural Anthropology, Duke Global Health Institute, Duke University,

Durham, NC, USA 


\section{Introduction}

The 2003 SARS pandemic heralded the return of quarantine as a vital part of twenty-first century public health practice. Quarantine, which refers to the physical separation of people who may have been exposed to a pathogen, requires apparently healthy individuals to surrender their freedom of movement in the name of public interest. Bioethicists grapple with justifications for this trade-off, recommending interventions that safeguard health systems while intruding minimally on people's basic liberties. When faced with a new infectious disease threat, public health actors must adapt general ethical guidance to fit specific epidemiological, cultural, and political contexts. Over the last two decades, SARS-CoV-1, MERS, Ebola, and other emerging infectious diseases have each posed unique sets of problems for applying quarantine ethics. This has taken place against a backdrop of technological advances that aid disease surveillance. However, increased global interdependence compromises the goal of disease containment. In this essay, we highlight social media testimonies from healthcare workers (HCWs), volunteers, and citizens in Wuhan, China, and discuss how people define and respond to ethical and legal obligations in the wake of SARS-CoV-2, popularly referred to as COVID-19. With this new body of evidence, we describe how both pandemic responses and pandemic ethics must adapt to the virtual digital age.

China was the first country to face a COVID-19 epidemic. Acting with relatively scarce information about the disease, China implemented a lockdown in Wuhan that would inform epidemic responses around the world. Nation-states, such as China, wield enormous power to enact and enforce quarantine and can allocate resources to mitigate its negative consequences; as such, they are a selfevident target for ethical analysis. However, co-workers, neighbors, and other members of physical and online communities can also act in ways that influence others' abilities to live fulfilling lives under quarantine. In Wuhan, and in other regions that responded to COVID-19 with lockdowns, the threat of infection and the ensuing response became defining features of people's lives, shaping their motivations and the consequences of their actions. In this paper, we will analyze vivid and personal social media documentation of the "new normal" under quarantine. By reflecting on the ways people frame and broadcast stories of sacrifice and support in a modern quarantine, we will contribute to the necessarily iterative process of expanding existing quarantine ethics principles to make them more coherent and responsive to emerging health needs in a twenty-first century quarantine.

Looking back on January 23, 2020, the start date of the Wuhan quarantine, many scholars might regard the immediate implementation of quarantine as an inhumane and unnecessarily severe policy that would trigger panic and criticism among the public (Agamben 2020; Zeng and Liu 2020). The decision to quarantine the entire city of Wuhan was announced at midnight and went into effect with only $10 \mathrm{~h}$ of advance notice. Only a small proportion of Wuhan residents were able to flee the city. The majority-Wuhan locals, plus some outsiders such as migrant workers who could not afford emergency travel - were "trapped" in the city with the virus. The quarantine, imposed 1 day before Chinese New Year's Eve, the most important traditional Chinese 
holiday for family reunions and visits, amplified the drama and upheaval of the moment. In the name of public health, around 10 million Wuhan residents minimized physical movements, suspended normal life activities, and contemplated the impact of possible supply shortages due to reduced transportation, all within the span of less than 24 hours. While these measures stoked anxieties and had an immeasurable economic impact, policymakers, HCWs, and citizens worked to mitigate this fallout, fulfilling obligations to quarantined individuals in different ways. We believe the Reciprocity Principle - typically used to describe aid the state provides to quarantined citizens can be expanded to interpret diverse and decentralized forms of aid that emerged in Wuhan.

\section{Reciprocity in Modern Quarantine: Foundational Arguments}

Existing literature on quarantine ethics tends to focus on the decision to use state power to implement and enforce a quarantine. For example, Wynia (2007), Bensimon and Upshur (2007), Rothstein (2015), and Gostin (2020) discuss quarantine from an impersonal, strategic point of view, listing epidemiological, geographic, and cultural variables that public health decision-makers ought to take into account before implementing a quarantine. Ross Upshur's 2003 article, "The Ethics of Quarantine," forms the basis of modern bioethical quarantine discourse. Upshur argues "there are two independent ethical considerations to consider: whether the concept of quarantine is justified ethically and whether it is effective" (393). Upshur argues that to satisfy these criteria, an ethically sound quarantine must limit harm (The Harm Principle), restrict liberty in a manner proportionate to the goal of disease control (The Proportionality Principle), compensate those quarantined in exchange for their sacrifices for the public good (The Reciprocity Principle), and be enacted by public health authorities who communicate the justifications for their actions and allow for processes of appeal (The Transparency Principle).

While all four of Upshur's principles are ripe for reinterpretation, we will focus on Reciprocity in this paper. As COVID-19 emerged in Wuhan, the authors of this paper scoured the Internet for insights into a pandemic that would soon test political and health systems around the world. While raw epidemiological data was readily available, we did not have the local knowledge or the expertise to use these data to evaluate whether China's response limited harm in a manner proportionate to disease control. Likewise, it is difficult to evaluate the transparency of China's response without having experienced it firsthand. We found the most compelling data from Wuhan to be citizens' lived experiences shared over social media. In video-blogs (vlogs), video diaries, and comments, we observed people making sense of what they lost when Wuhan entered its lockdown. Ethical frameworks like Upshur's address public health crises in broad strokes, but as we argue here, must be interpreted and tailored to guide us through each specific instance of quarantine. In this essay, through qualitative, ethnographic analysis, we show how widespread community-level enactment of the principle of Reciprocity animated citizen-led self-help movements in the early days of the Wuhan quarantine.

Broadly speaking, Reciprocity refers to the exchange of benefits. When Upshur defines his Reciprocity principle, he describes an exchange in which quarantined citizens sacrifice income and freedom of movement to make it easier for the 
government to meet public health goals. In return for a compliant public, an ethical government would provide supportive services such as paid sick leave, assistance with food and shelter, and special protections for vulnerable populations (Upshur 2003, 394; Gostin et al. 2020, 10). Nevertheless, even if the Reciprocity principle can be met to compensate people affected by the quarantine, adequate and fairly-dispersed benefits rarely reach all needy citizens. HCWs, who navigate the quarantine both as essential workers for the state and as citizens after they return home from work, experience a double sacrifice: they are both residents within the quarantined area and lifesavers on the frontlines, daily facing the possibility of their own infection as well as bringing it home to infect their own household. To address sacrifices made by HCWs, other ethicists advocate for meaningful limits on the "duty of care" for HCWs who take on risks beyond the scope of their contractual and social responsibilities in a pandemic (Cox 2020). In exchange for HCWs' outsized role in preventing widespread death and suffering, people and governments who benefit from health and order should comply with these public health recommendations by affording HCWs higher social status and funneling adequate personal protective equipment (PPE) to HCWs to reduce their risk of infection.

The exchanges described above are bilateral and direct, with the outlined parties ("HCWs", "citizens", "the state") conveying benefits to and receiving benefits from each other simultaneously. However, societies also rely on benefit exchanges that are multilateral and complex. As Molm et al. (2007) explain, Reciprocity also takes place through indirect exchange, in which actors provide benefits unilaterally across a network of actors and may not receive benefits from the same actor they helped in the first place. In its most diffuse form, Reciprocity occurs through generalized exchange. The authors raised "helping a stranded motorist, giving blood and reviewing journal articles" as examples of "pure-generalized" exchange, actions that convey clear benefits without a clear source of compensation (208). In Wuhan, selfless frontline HCWs and citizens engaged in mutual aid to deliver benefits to patients and vulnerable citizens not because they expected direct compensation from the people they helped, but because it was rewarding to them personally to establish a system of support and care in an extraordinary time.

An effective response to a public health crisis relies on people to engage in good behavior without an obvious reward in sight. Molm et al. (2007) also observe these generalized contributions risk non-Reciprocity: in other words, as actors are added to a "chain" of indirect Reciprocity, the delay between delivery and receipt of benefits becomes amplified. When the chain of actors grows large enough, it becomes difficult to identify people who only receive, but do not offer, assistance. In diffuse, sprawling societal networks, it is easier to get away with cheating and free-riding than in smaller groups. Therefore, the sacrifices citizens make in quarantine make them vulnerable to neglect and exploitation. Thus, when people are rewarded for these sacrifices in an environment where they might otherwise expect to be overlooked, they now feel that others care about them. When Reciprocity is repeated across different social strata, this feeling of regard for others builds and reinforces norms of trust and solidarity in the broader society. According to Cammett and Lieberman (2020), these are contagious resources that yield cumulative benefits: feelings of solidarity can drive further contributions to the public good. These contagious resources are commonly found and can be tapped, at the local level. In the analysis below, through our focus on smaller units of 
social organization, we identify and describe praiseworthy efforts by Wuhan citizens as evidenced by both national and local aid and the sharing of online diaries. In addition, by describing the moral landscape of a modern quarantine through ethnographic details, we highlight the ways in which existing ethical frameworks may not be well-suited to guide and evaluate public health decisions in a post-COVID-19 world facing as-yetunknown, but probably likely to emerge, new infectious diseases.

\section{Reciprocity in Modern Quarantine: New Approaches}

While our analysis departs from the ethicists' framework synthesized in the above section, we argue it is essential to incorporate other frameworks into our discussion in order to illustrate a more elaborative understanding of Reciprocity during quarantine. First, we note that certain stressors caused by COVID-19 may exacerbate inequalities among frontline HCWs. By employing a model of HCWs' needs based on the context of Chinese hospitals (Concern \& Love System, discussed below), we highlight that HCWs' needs are an essential part of the Reciprocity principle, and in a pandemic, meeting these needs demands more nuance from the policymaking process. Second, we articulate how ethical practices might be defined and interpreted by non-policymakers in a pandemic by attending to the emerging phenomenon of mutual aid and analyzing it through relevant social theories. Ultimately, our analysis is informed by three theoretical threads: the ethics of quarantine, with a focus on the principle of Reciprocity; the model of HCWs' needs built upon the Chinese context; and social theories on mutual aid. This section will articulate the second and third threads, discussing how they have complicated the ethics of a standard support package in the modern quarantine.

As mentioned, the Reciprocity principle calls for compensation in exchange for sacrifice, for which HCWs constitute a special group bridging the state and its citizens while also experiencing their own double burden of risk. To inform a complete set of compensating policies for front-line HCWs in future health crises, a guiding system named the "Concern \& Love System" was recently proposed by Chinese scholars (Jiang et al. 2020). In February, the height of the COVID-19 crisis in Wuhan, Jiang et al. conducted online surveys among frontline HCWs to gauge their needs. They collected 2868 questionnaires, most of which were from Hubei Province (Wuhan) and Sichuan Province. In addition to these survey responses from frontline HCWs, Jiang et al. also analyzed policies published by the Chinese state council and its affiliated ministries and commissions during the first month of the outbreak: 11 on logistical support, four on protective support, and two on family support. They noted that these policies partially strengthened preventive and logistical supports, but a gap still existed between the compensating policies and the exact needs as expressed by HCWs in the survey data.

To address the gap and inform future compensation policies, Jiang et al. (2020) proposed the Concern \& Love System, based on Maslow's Hierarchy of Needs and Herzberg's Two Factor Theory. Both classic theories identify human needs beyond physical bodily requirements. Maslow ([1954] 1979) advocated for attention to the subjective needs of respect and self-actualization, while Herzberg (1959) highlighted the importance of actively motivating people's commitment to participate in assistance activities. Psychological support is easily neglected in the early stages of a quarantine 
due to the necessity to prioritize focus on logistics and materiel. The Concern \& Love System proposed by Jiang et al. emphasizes the equal importance of five areas of support: protective, logistical, psychological, family, and cultural. While the needs of HCWs are featured in the Reciprocity principle mentioned above, Jiang et al.'s system is particularly relevant to our analysis because it is based on both widely accepted social theories and their survey findings are specific to the Wuhan case. Drawing on our qualitative data of the lived experiences of Wuhan's survivors, we both confirm the relevance, validity, and necessity of Jiang et al.'s system and extend and deepen it to explore ideas for a new quarantine ethics framework.

In addition to the Concern \& Love System, this paper also borrows from theories of mutual aid to explore its reconfiguration as an emerging global phenomenon worthy of re-interpretation in the COVID-19 context. Social theories of mutual aid trace back to Peter Kropotkin's 1902 book Mutual Aid: A Factor of Evolution. According to Kropotkin, cooperation among all sentient beings (including human) is the main factor driving evolution, not competition and selection. Particularly in the Chinese context, Tsu (1912) regards mutual assistance in various aspects of the society as displays of philanthropic spirits embedded in Chinese traditions, such as virtue and kindness promoted in both Confucius's and Mencius's thoughts. If Kropotkin and Tsu investigate the foundations of mutual aid by tracing its history and traditions, then recent works on mutual aid consider its functions and possibilities by attending to the current moment of a global pandemic. Spade $(2020,134)$ considers mutual aid to be a set of arrangements of "bottom-up strategies" that contrast with traditional state and charity assistance and highlights its utility in actively mobilizing the collective to confront social injustice, disasters, and other crises. Social mobilization and solidarity formation are echoing around the globe, marking mutual aid as a significant form of Reciprocity universally adopted by diverse communities in the pandemic (Springer 2020; Domínguez et al. 2020; Tolbert 2020). Wuhan, the first city where a COVID-19 outbreak occurred and robust quarantine was implemented, is no exception.

Mutual aid is not necessarily concerned with political gestures or agendas. Anthropologist David Graeber applauds the rediscovery of Kropotkin's conceptions of mutual aid among worldwide social movement promoters, but clarifies that Kropotkin's insights are "not just about the nature of government, but the nature of nature - that is, reality - itself" (Graeber and Grubačić 2020a, b). In other words, before entering the realm of politics or the process of politicization, Graeber reminds us that mutual aid refers to animal beings' initial, spontaneous, and collaborative reactions to crises. For example, we found that rather than confront government and institutions, mutual aid volunteers in Wuhan believed their purpose was to supplement the deployment of governmental assistance. Spade (2020) suggests mutual aid represents a gesture of political protests that aim to challenge structural violence. However, in contrast, we found that mutual aid groups in Wuhan appeared to sidestep politics or calls for accountability in favor of simply trying to address pandemic needs. Our analysis identified a strong sense of citizen-focused solidarity that avoided, or even transcended, political intentions. Our three-point theoretical approach more accurately accounts for these various modes of assistance in Wuhan and informs out call for a different approach to the Reciprocity principle in pandemic times. 


\section{Logistical Support is not Enough}

Among the various HCW needs during a pandemic and quarantine, logistical support to protect from infection is foundational. However, logistical supports beyond physical health and workplace performance were not well satisfied in the Wuhan quarantine. We present evidence from images and videos posted to TikTok (Douyin) from the early stage of the Wuhan outbreak (late January-late March, 2020) to analyze how HCWs benefited/did not benefit from reciprocal practices in Wuhan. We also researched literature on ethical issues related to COVID-19 in Wuhan during this period in newsfeeds, blogs, and academic journals. In this and the following section, we describe the lived experience of HCWs by analyzing the impact of state actions on their well-being, and ask if HCWs should have been better compensated during this chaotic period of the epidemic. Due to frequent, close contact with COVID-19-positive patients, HCWs are at high risk of iatrogenic transmission to themselves, and then as potential hosts of further virus transmission to others. Under the generally well-described Duty To Care/Treat paradigm (Malm et al. 2008), state and healthcare systems must provide HCWs with adequate equipment for protecting both themselves and their patients. However, reports indicate that these kinds of basic needs were not met in Wuhan. For example, by February 24, 2020, the Chinese government reported that 3387 HCWs were infected with COVID-19, more than 90\% (3062 cases) came from Hubei Province, where Wuhan is the capital city (China.com 2020). Social media posts by HCWs at the beginning stages of the quarantine chronicle a critical lack of PPE, this prompted HCWs to take ad hoc precautions to protect themselves. For example, to save supplies, HCWs did not remove their goggles or protective suits until they finished their daily work, keeping them on through their entire shift despite the fact that they were fogged with condensation from their exhalation and perspiration (Figs. 1, 2, 3, 4) (Jiangxi TV 2020; People's Daily+ 2020). Figures 5, $6,7,8$ show the damage done by frequent hand washing and wearing masks for long periods of time (People.cn 2020). To minimize trips to the restroom, which would require replacing PPE suits, HCWs did not drink water and wore adult diapers under their PPE suits (Dragon TV 2020; CCTV.com 2020).

Fig. 1 Foggy goggles. Reference: Jiangxi TV 江西卫视 (2020)

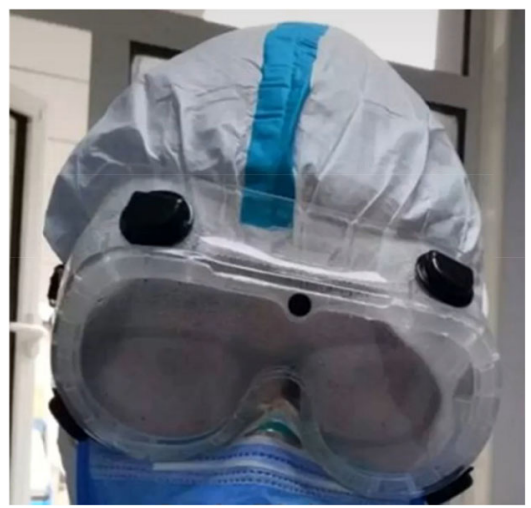


Fig. 2 Foggy goggles. Reference: Jiangxi TV 江西卫视 (2020)

Fig. 3 Wet suit. Reference: Jiangxi TV 江西卫视 (2020)

Fig. 4 Wet suit. Reference:

People's Daily+人民日报+ (2020)
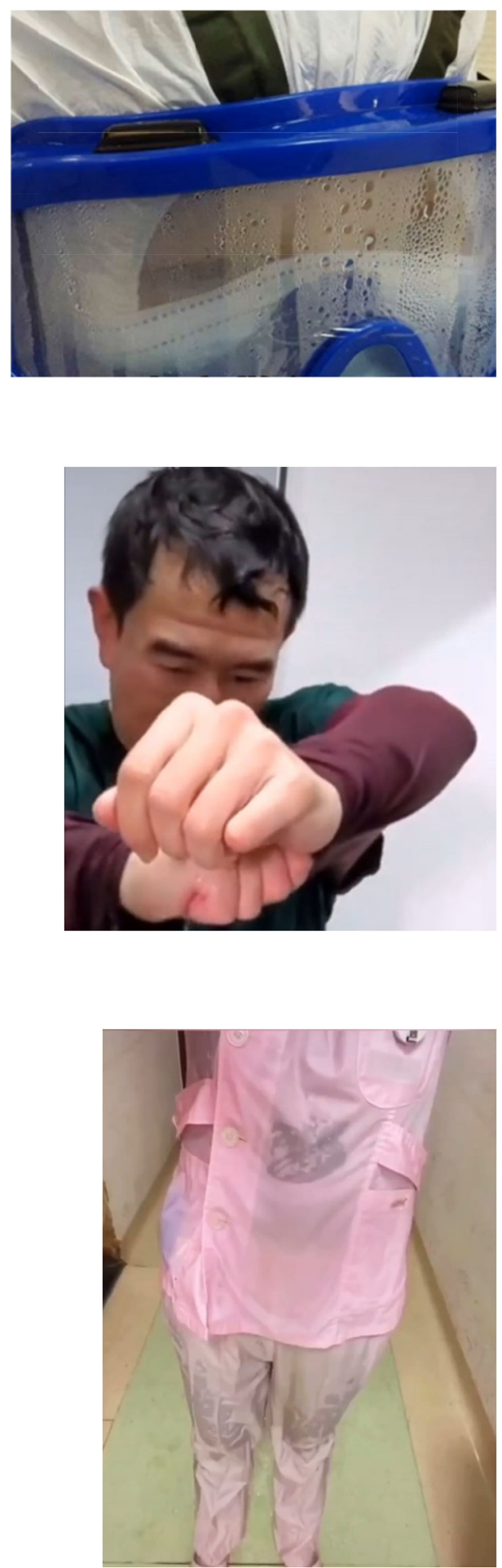
Fig. 5 Hands of $\mathrm{HCW}$ at end of long work session. Reference:

People.cn人民网 (2020)

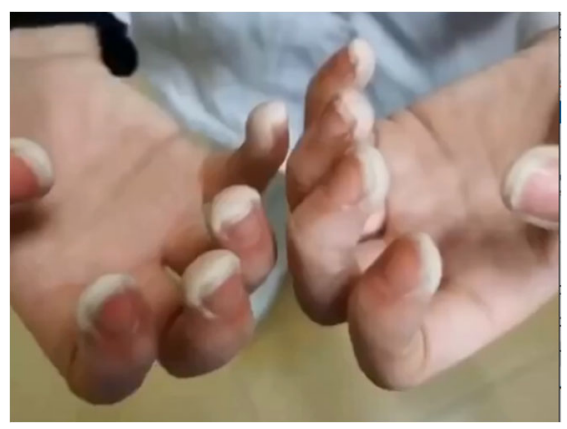

Fig. 6 Hands of HCW at end of long work session. Reference:

People.cn 人民网 (2020)

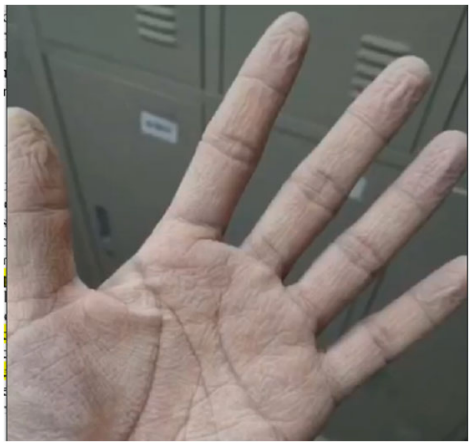

Fig. 7 Face of HCW at end of long work session. Reference: People.cn 人民网 (2020)

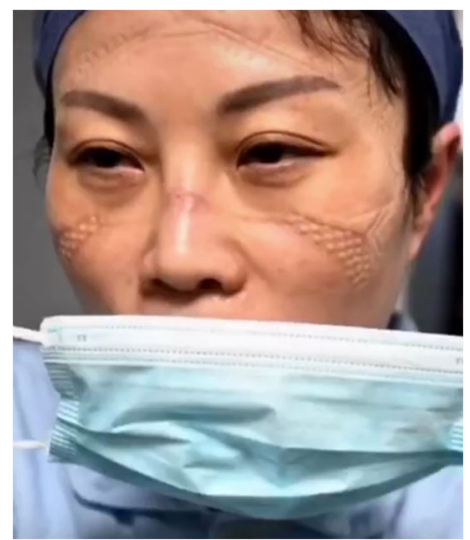


Fig. 8 Face of HCW at end of long work session. People.cn人民 网 (2020)

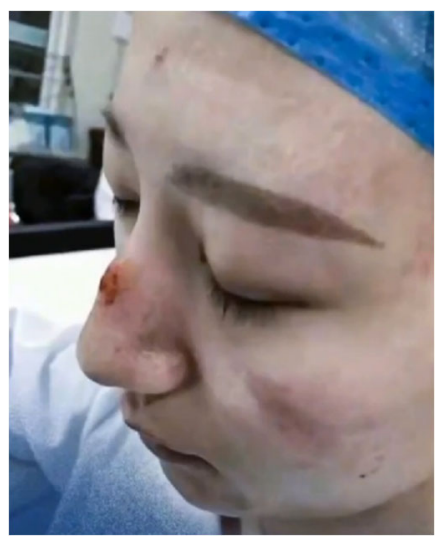

In addition to the difficulties caused by lack of PPE, other aspects of caregiving work in the wards of Wuhan hospitals wrought havoc on HCWs' bodies. First, to contend with high temperatures inside the wards due to restrictions on air conditioning, HCWs plunged their extremities in ice cubes to cool down (Figs. 9, 10) (PLA Navy 2020; Hubei News 2020). Second, HCWs in Wuhan were assigned overwhelming workloads, especially in the early stages of the quarantine, to accommodate waves of panicked Wuhan citizens flooding into fever clinics seeking care (Fig. 11) (Cover News 2020). On January 26, 2020, all fever clinics in Wuhan remained open continuously (24/7) for diagnosis and treatment and HCWs were ordered to work extra hours (Hubei TV 2020). Wenhong Zhang, head of the Center of Infectious Diseases at Huashan Hospital of Fudan University, reported that front-line HCWs worked more than 16 hours every day (Qingfengxia 2020). One doctor reported to the media, "I only had only three hours daily sleep for almost two weeks" (CCTV News 2020). More vividly, in these images, a nurse was seen falling to the ground after hours of packing and disposing of medical waste (Figs. 12, 13) (Hubei Daily 2020). Third, because HCWs in Wuhan were simultaneously professional caregivers and quarantined residents, this dual status doubled their responsibilities and demanded twice the sacrifice. At work, they were expected to provide essential care at great risk to their own health,

Fig. 9 HCWs use ice cubes to cool down. Reference: PLA Navy人民 海军 (2020)

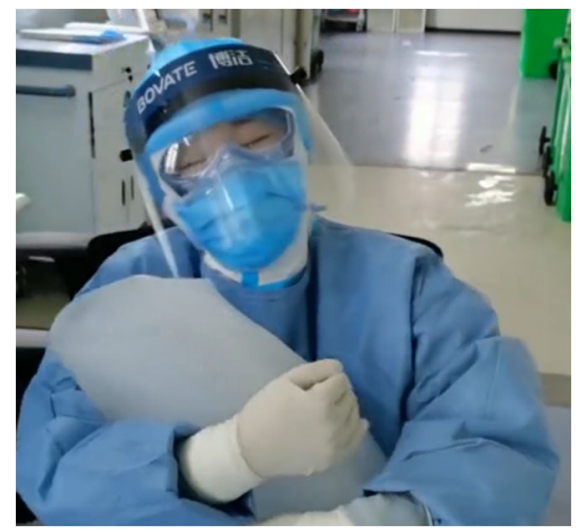


Fig. $10 \mathrm{HCWs}$ use ice cubes to cool down. Reference: Hubei

News 湖北新闻 (2020)

Fig. 11 Scene of people lining up in front of fever clinic. Reference: Cover News 封面新闻 (2020)

Fig. 12 An exhausted nurse falling to the ground. Reference: Hubei Daily 湖北日报 (2020)
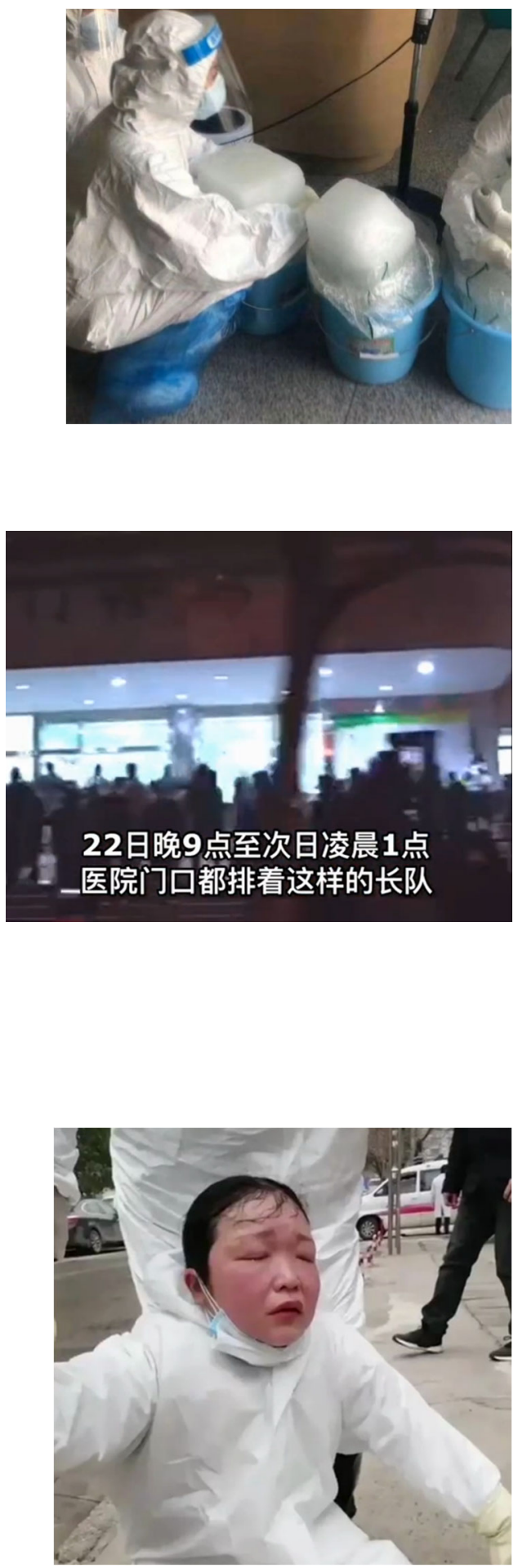
Fig. 13 An exhausted nurse falling to the ground. Reference: Hubei

Daily 湖北日报 (2020)

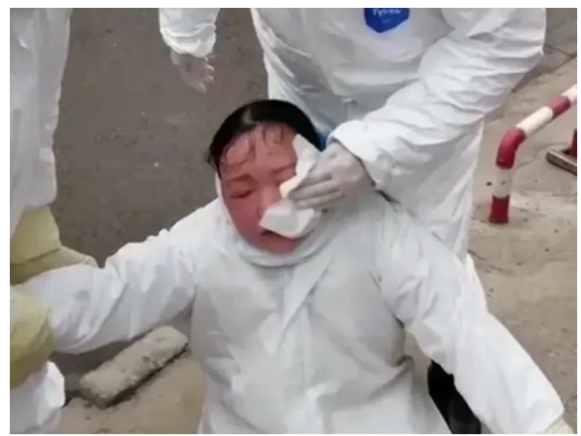

yet at the end of their shifts, they had to quarantine themselves from others to prevent further disease spread. Ultimately, lack of PPE, poor working conditions, lengthy working shifts, and increased responsibilities placed unmanageable and unfair burdens on HCWs' shoulders. In the next section, we follow Jiang et al. (2020)'s Love \& Concern model to examine one piece of evidence of the psychological harm endured by HCWs through a gendered lens: the case study of nurses' haircuts and the ensuing controversy that spilled into social media.

\section{Psychological Support Gone Wrong: Haircuts and Gender Disparities in Pandemic Burdens}

On February 15, 2020, a vlog published by the Gansu Provincial Maternity and Child-Care Hospital (GSMCH) caught the public's attention. This vlog recorded 14 female nurses having their heads shaved (Joe W 2020). These nurses were selected to be in the third medical team sent by Gansu Province to assist Hubei Province. Because scenes of young female nurses crying while seeing their hair drop to the floor were quite discomforting, controversies quickly arose on social media. Some questioned the necessity of total hair removal: "Does it need to be bald? Short (as for males) does not work?"; others wondered if these nurses had a choice at all: "If these nurses received such bald haircut voluntarily, why are these girls crying?" (Wang and Peng 2020). Faced with these unexpected comments, an anonymous health official from GSMCH explained that all the nurses voluntarily cut off their hair for "self-protection" and for "better performance" in a healthcare setting (Wang and Peng 2020). However, we interpret this response below (from another news source) to indicate that the hospital officials probably neither obtained consent from these HCWs nor informed them of this additional requirement before they made the decision to assist Wuhan:

We prioritize the safety issue... There is no standard of the hair style before departure... Such action is voluntary and I think we should consider safety beyond discussing whether such action is correct or not. Let's save the comments until further standards are published after succeeding the battle. Don't let our workers battle with tears at the front line. The public should please stop putting pressure on them. ${ }^{1}$ (WeVideo 2020)

\footnotetext{
${ }^{1}$ Original text: “我们首先考虑安全的问题... 国家又没有标准你去之前要理个什么样的发型...首先这个事情是自愿做的， 我觉得这个事情, 我们不要讨论这个东西对与错了, 更应考虑安全问题. 整个战役之后, 等国家有了标准自有评说. 不要让在 前线的战斗人含泪奔跑, 后方的人不要在增加压力了."
} 
While this explanation seems to justify the controversial decision, it raises additional questions. First, the nurses were not aware that they needed to shave their heads bald until the very last moment before departure. Whether or not this requirement would have changed their decision to support Wuhan is unknown. In any case, we argue that they deserved the right to know and to take this factor into consideration before agreeing to volunteer. Second, by stating "don't let our workers battle with tears at the front line," this official seemed to pass the blame to social media commenters for increasing the pressure on the nurses and unnecessarily evoking their sadness. This comment is confusingly self-contradictory because it was the hospital administration that initiated the haircut action and further publicized the event on social media. While the necessity of haircut is questionable enough, the fact that the haircutting process was also video-recorded and published to social media invites further ethical considerations.

While some people were encouraged by seeing Chinese HCWs bravely sacrificing their own hair to fight the virus, the question remains whether it was permissible, even with consent, to exploit these women's pain for propaganda (Chen 2020). These HCWs' reactions were instantly made public, and their faces were identifiable. Their pain was used to promote them as heroes who were expected to make sacrifices for the public good, willingly or unwillingly. Although we do not deny the potential inspirational value of such propaganda, we want to point out that praising a certain group as heroes can invite the risk of depriving them of basic human rights, especially in the context of COVID-19 where resources were scarce and caregiving demands were increasing everywhere. Echoing Cox's (2020) concerns, by calling HCWs "heroes," expectations increase that they will continue to contribute to others' benefits at great cost to their own personal well-being (512). In the case of the nurses' haircuts, we see multiple layers of harm. For example, we suspect these nurses could not exercise their right to refuse the hair cutting because they were not informed until the day before departure. In addition, the fact that the videos went viral on social media likely intensified the psychological trauma they were already experiencing.

We interpret the decision to widely publicize the haircut incident on social mediaas a means to give encouragement to other HCWs - as a form of "ritual communication." According to the work of media studies scholar, Eric Rothenbuhler, ritual communication conveys symbolic meanings through performative actions in an effort to trigger emotions or strengthen certain social ideals or identities (Rothenbuhler 1998). In the haircut case, the space of hospitals symbolized the "battlefield" implying danger and uncertainty, while female HCWs who were involved in the ritual of "haircut" symbolized the soldiers and heroes who were expected to fight on this "battlefield" at the cost of their personal interest (Bi and Piao 2020). HCWs' responsibilities were therefore extended beyond saving lives. Deployed by state propaganda, female HCWs now served as the symbolic characters for the purpose of motivating the public, enhancing acknowledgement towards sacrifices, and strengthening national confidence in the battle against COVID-19. While it achieved this end to some extent, that is, offering "psychological support" for residents within the quarantine, in Upshur's framework, the officials overlooked the fact that HCWs' are owed reciprocal compensation for their own sacrifices. These young female volunteer nurses embody their role both as state's agents (in China's case) to save lives on the frontline and as members of a vulnerable group whose physical and psychological needs are overlooked in many public health crises. 
In addition, gender disparities underpin the haircutting incident. The National Health Commission of the People's Republic of China reported that of 42,600 volunteer HCWs traveling to Hubei, two thirds $(28,600)$ were nurses. Further, of these 28,600 volunteer nurses assisting Hubei, 25,300 were female, accounting for nearly $90 \%$ of all nurses serving COVID-19 patients in Hubei (Liu 2020). In addition, gender disparities reflect the disparate level of risk and sacrifices made by male and female HCWs. Most male HCWs were doctors who were less exposed to patients compared with nurses. For men, short hair was already the cultural norm, and thus, many had already cut their hair short enough to reduce chances of infection. Cases of male HCWs shaving their heads bald were also reported, but very rarely depicted on social media (Zhang 2020; Zhao 2020). By comparison, the vlog of female nurses' haircuts captured the public's attention precisely because the young women had to give up something precious and valued by their gender's norms in order to fight against COVID-19. In this case, the additional stress experienced through this haircutting incident is related to both gendered norms of female beauty and risk inequities due to the hierarchies within the healthcare profession.

\section{Online Solidarity as Citizen-Driven Reciprocity}

Having examined the gaps in the Chinese state's practices of Reciprocity, this paper now moves to an analysis of Reciprocity as enacted through citizen volunteer mutual aid societies that responded to people's urgent daily needs in Wuhan. Mutual aid, in this context, refers to informal, temporary, non-governmental assistance groups that seek to rescue fellow citizens. Normally, these groups do not function according to any significant rules or governance structures of their own, yet they provide care within the constraints of state regulations. To better understand the actions of mutual aid groups as Reciprocal activities in the extraordinary context of the Wuhan quarantine, we analyzed over 400 minutes of vlogs culled from the website Sina Weibo over the period of January 23-April 8, 2020 , coinciding with the start and end dates of the Wuhan quarantine. To supplement our Internet research, we also interviewed one representative Wuhan mutual aid volunteer, Zhizhu, who joined the mutual aid teams from the beginning of the quarantine and continuously recorded his activities in his series of vlogs (Zhizhu and Ni 2020). Our conception of mutual aid encompasses not only the assistance activities recorded in the vlogs, but also the production of the vlogs itself. The assistance activities recorded by vloggers directly fulfilled Wuhan citizens' urgent and essential needs. At the same time, the vlog recording of these mutual aid practices also seemed to offer psychological support to people suffering through the quarantine. Our criteria for selecting vlog material for analysis depended on the popularity (view counts) and continuity (whether the creator continued to post material) of the vlog. For example, the series of vlogs entitled "Wuhan Quarantine Diary" created by Zhizhu (2020a) has both considerable view counts and comprehensiveness throughout our research period. Of the many themes that emerged from the 400 minutes of vlog data, we focus our analysis here on two types of citizen-produced vlogs: recordings of everyday life and the activities of mutual aid societies. The first is typically presented in a diary-format 
with intimate, first-person reflections and musings spoken directly to the camera; this echoes the respect, support, and non-discrimination embodied in Upshur's definition of Reciprocity. The second type of vlog highlights the utilitarian fulfillment of food, shelter, and other supplies. The emergence of these two types of vlogs offers reflection on both body and mind and likely fortified mutual aid volunteers to confront the sacrifices necessary to contribute to the state's ultimate goal: to enhance "epidemic prevention and control" (Hubei Provincial People's Government 2020).

As physical contact was restricted to the bare minimum, communication on social media immediately emerged as a substitute for traditional interactions, thereby relieving the abrupt interruption of normal life. A typical example is the explosion of Wuhan residents' online diaries recording daily life as experienced during quarantine. The diaries mostly contained ordinary activities such as eating, sleeping, conversing, and exercisingquotidian details that suddenly seemed larger-than-life against the unprecedented backdrop of the pandemic. Quarantined people who attempted to recreate their previous normal life were hindered by shortages of basic daily goods. For instance, most households simplified their meal plans in anticipation of a future decrease in food supply, thereby amplifying the luxury of the traditional Chinese New Year's Eve feast. Our analysis suggests that most of these social media recordings were spontaneously produced rather than deliberately organized, as they appear piecemeal and fragmentary. However, it is precisely through such an unintentionally formed collection of everyday details that we can better understand how Wuhan residents mediated these disturbances to their daily lives.

Fundamentally, these diary creations were intimate personal expressions as well as outlets for intense emotions. They satisfied Wuhan residents' desire to speak out about their living experiences during the quarantine and soothed negative emotions such as fear and anxiety. By narrating real situations and personal stories, diary creators dispelled rumors about Wuhan on social media which exaggerated the level of disorder and chaos inside the Wuhan quarantine. Specifically, the words "real" or "true" appear frequently in many diaries. For example, titles like "Real Diaries of a Girl Living in Wuhan" (Xiao Hang 2020) and "Real Living Diary of a Wuhan Native in the Epidemic" (Jiang 2020) were typical and numerous. To respond to voices from within the quarantine, audiences outside Wuhan "like[d]," "share[d]," and "comment[ed]" (typical features on social media platforms such as Sina Weibo) on that content to show support. Both diary creators and audiences tended to project hope and encouragement despite occasional displays of frustration. For example, the popular diary creator Zhizhu (2020a) conveyed obvious optimism in the opening and ending sequences of all his vlogs, although negative emotions sometimes emerge in his soliloquy scenes. Typically, his vlogs start with a sequence of the beautiful, sunny Wuhan morning scenery and then end with quiet and peaceful night scenes, accompanied with soft music. Drawing from counts on his top ten most viewed vlogs on Bilibili, expressions of hope like "Wuhan, stay strong!" are among the most frequent remarks on his works (Zhizhu 2020h). Indeed, in our interview, he told us that one of his biggest motivations of filming the situations in Wuhan was to offer encouragement and hope to people within the quarantine (Zhizhu and Ni 2020). In the Wuhan quarantine, the emergence of online expressions like diary creations formed a productive public space through which mitigated negative emotions caused by the sudden quarantine and offered possibility for reciprocal and iterative exchanges of diaries in the virtual space. 


\section{Filling in the Gaps of the State's Response}

While online expressions provided what Upshur valued as "psychological support," other measures were still required to target urgent problems. For example, despite the limits discussed above, HCWs from around the country were relocated to support Wuhan. So, too, were food and other necessities. Chinese diasporas around the world sent essential resources such as facemasks from their homes outside China to the center of the emerging pandemic. These measures effectively slowed the spread of infection and helped the city regain order, restoring the promise of a future for people living within the quarantine. In the first 3 weeks of the quarantine, Wuhan citizens, concerned with supply shortages and limitations on physical movement, expressed their complaints and anxiety widely (Liu et al. 2020). However, their expressions later turned positive, showing care for others (e.g., "please protect yourself"), hope for reopening the city (e.g., "what is the first thing you would do once reopening"), and more importantly, offering understanding and support for the quarantine policy (e.g., "I am Wuhan native. I support the quarantine policy."). Ultimately, assistance from various sources in the physical space resolved practical issues, while online communication offered psychological support to residents within the quarantine. To use the words of Cammett and Lieberman (2020), the sense of solidarity became increasingly contagious. Through various approaches, societal practices of offering care and support to those who sacrificed personal freedom accord well with the principle of Reciprocity.

Nevertheless, Upshur's definition focuses on assistance from outside the quarantine on the side of policymakers, while barely addressing practices among people within the quarantine. For a nuanced understanding, this paper notes that local mutual aid societies, temporarily established by Wuhan residents themselves, should also be understood as reflecting and building ethical norms in a quarantine. Mutual aid volunteers dealt with demands left unmet by policymakers while frontline HCWs focused on hospital-based care. Some mutual aid volunteers were "couriers" delivering supplies. Some were "drivers" offering rides. Still others were "story recorders" sharing otherwise unseen narratives with people outside the quarantine. Home-cooked meals and essential supplies were distributed to those who needed them (Zhizhu 2020d). Owners of private hotels near the hospitals offered rooms to HCWs who had difficulty commuting between homes and hospitals due to restrictions on public transportation (Zhizhu 2020c).

The story is different for marginal groups made even more vulnerable by the sudden changes wrought by the quarantine. Many migrant workers, themselves Chinese citizens who traveled to Wuhan for job opportunities, became homeless in the Wuhan quarantine when they lost their jobs and could no longer afford their temporary accommodation. Although the government attempted to help this group by offering assistance funds, the application procedures were so complicated, and most migrant workers and homeless people could not provide all the necessary documents required to get access to the state support. According to Zhizhu, migrant workers knew about this assistance fund, but it was difficult for them to answer all the required questions, and some did not even have an official identity card (Zhizhu and Ni 2020). Ai, Weiwei in his powerful 2020 film Coronation, tells the story of a migrant worker trapped in the Wuhan quarantine and forced to live in a parking garage.

While the intention of governmental assistance was to help this vulnerable group, actual implementation was far from effective. In contrast, local mutual aid volunteers 
collected donations to support them, and the assistance provided by mutual aid societies depended on who most needed help (Zhizhu 2020e, f). They first identified migrant workers' challenges and needs, sought donations from the internet, and rapidly sent support onward to those who most urgently needed funds. This example illustrates that mutual aid societies in Wuhan followed different operational structures compared to stateled and traditional charities. Without paperwork and complicated procedures, mutual aid societies relied on bare-bones administration in order to maximize efficiency. Unburdened by criteria that might restrict state or charitable giving, mutual aid groups offered assistance to anyone in need regardless of gender, race, ethnicity, or nationality.

Conflicts between the state and mutual aid societies emerged when volunteers' activities were hampered by the state's temporary regulation. For example, the state required volunteers to apply for driving permits but set strict requirements for applications, which restricted volunteers' movements (Zhizhu 2020g). In another strategic reaction to the mutual aid societies, the government attempted to co-opt mutual aid volunteers into its official volunteer teams by paying them a salary. It was certainly important to reward their assistance, but some volunteers suspected that receiving payment changed the nature of volunteering itself. For people with this mindset, helping the city out without asking for anything in return was highly valued volunteering, while getting paid transformed the volunteer into a wage laborer for the state. From our interview with Zhizhu, and content from his vlogs, the primary motivation of most volunteers was to save the city and their fellow citizens, not to be compensated (Zhizhu and Ni 2020). Mutual aid volunteers in Wuhan considered their actions as a way to fill the gaps in the state assistance. Zhizhu, who has filmed and talked to many other volunteers, emphasized that volunteers were aware of the fact that citizens' capabilities were limited to small-scale projects and only government had the capacity to mobilize significant capital resources (e.g., by relocating HCWs nationwide or initiating the construction of mobile hospitals) (Zhizhu and Ni 2020). Such an acknowledgement, common among volunteers, is vital to our understanding of the nature and functions of mutual aid in the Wuhan case. What we observe in Wuhan differs from the anarchism described by Spade (2020) and other western scholars. Mutual aid practitioners in Wuhan had little interest in pursuing permanent structural transformations, let alone fight the state's authority. Overall, the major achievements of mutual aid volunteers in Wuhan was caring for unmet needs and supplementing the state's assistance. Intentionally or unintentionally, despite occasional conflict and disharmony, the state and mutual aid assistance in the Wuhan case ended up in a collaborative relationship with a shared goal to cure the residents and restore the city.

While Upshur's definition of principle of Reciprocity weighs more heavily on the state's responsibilities, our analyses of citizen-produced vlogs found that mutual aid both within and beyond the quarantine, whether in the form of online diary-production or offline assistance actions, should also be considered as essential practices of Reciprocity. People outside the quarantine sent support and care to Wuhan citizens, while Wuhan citizens themselves established temporary mutual aid societies around the city to resolve issues for each other. All these efforts were critical supplements to the state's reciprocal measures. However, in the context of the COVID-19 pandemic, high rates of infection and the extended asymptomatic incubation period further complicated the question of citizen-to-citizen Reciprocity. Any assistance requiring sharing of physical space posed potential risks to both helpers and those helped. In contrast to 
permanent hospital and clinic spaces, mutual aid societies in Wuhan were controversial because they were temporary and far less organized. There were indeed cases of infection that stopped an entire volunteer group from further activities (Zhizhu 2020b). Fortunately, most volunteers in Wuhan were very aware of the potential risks. Thus far, no one has reported any wide-ranging infections caused by mutual aid activities. Risks were reduced by volunteers' measures such as wearing facemasks throughout their journeys, using disinfectants after each ride, and delivering supplies without physical contact. Here, we find a limitation on our extended concept of Reciprocity and an opportunity for bioethical interpretation. The duty of Reciprocity drives mutual aid, but that in turn can cause unintended harm. Without ethical structures to guide citizen-led groups, state sanctions may be necessary to rein in the risk of ill-prepared actors; however, these very same "protective" sanctions may also impede vital aid.

Returning to Upshur's principle of Reciprocity and the responsibilities of policymakers, we suggest this is the critical lesson from the case of Wuhan mutual aid: rather than attempting to co-opt citizen-driven assistance activities which would likely reduce their effectiveness and innovations, the state can and should be more supportive and collaborative. The state should acknowledge the usefulness of mutual aid and respect its function and organization, without fearing that mutual aid assistance might overshadow state assistance. Particularly in the context of Wuhan, mutual aid volunteers and the state were not in a directly antagonistic relationship. Before worrying about the potential power created by the collective of mutual aid, the state would do better to first consider that these citizen volunteers were acting with the aim of helping the city and, indeed, played a critically important role doing so.

\section{Conclusion}

Our paper interprets the testimonies of people in Wuhan to demonstrate how an ethical framework usually enforced at the level of state-driven policy also needs to take into account citizen-led actions. In Wuhan, citizens supplemented state policies meant to maintain well-being during the COVID-19 pandemic. While quarantine is intended to prevent harm caused by infectious disease, a protracted and wide-ranging quarantine places economic and social strain on society. At the end of his piece, Upshur (2003) poses the fundamental question policymakers must contemplate before implementing a quarantine: "Do the potential benefits of quarantine outweigh the possible adverse consequences?" (394). The benefits of quarantine are obvious but difficult to measure against less restrictive alternative strategies. We chose to expand on the principle of Reciprocity to clarify the latter half of Upshur's question. If adverse consequences are measured in terms of human suffering, then people who contemplate quarantines must have an accurate and specific idea of how people suffer in conditions of quarantine. By describing how suffering was witnessed, shared, and addressed in Wuhan, we imagine solutions that can inform future interventions against infectious disease to be more decisive, effective, and at the same time, compassionate towards their subjects. By exploring the agency of the citizens of Wuhan, we imagine ways in which nonstate actors can and should take part in these solutions. 
Using the lens of Reciprocity to analyze the shortcomings of the Chinese state response to COVID-19 in Wuhan, Hubei Province, reveals new opportunities to respond to some of the complex problems that emerge in a pandemic. According to our first-person accounts, frontline HCWs endure stress both as medical practitioners and as quarantined people. Reciprocity demands that states provide adequate logistical support as well as psychological support for HCWs. The example of the female nurses' haircuts highlights the extra sacrifice society called for from female HCWs but not from men. Mutual aid activities, demonstrated through online solidarity and material generosity in Wuhan, gives us insight into how smartphones and Internet connections can facilitate people who want to assist their community. To leverage this success, we advise all parties (citizens, local government, state) to re-orient their attitudes and capacities towards a shared goal of fostering these new forms of reciprocal practices, not suppressing them. For the state, this may mean ceding elements of surveillance and control over people's abilities to access and use information. Community figures who emerge to lead volunteer organizations should engage in dialog with scientific experts and policymakers to inform safe and effective strategies. Through open communication, citizens can articulate needs ignored by the state's response, and states can more accurately gauge the extent to which citizens can contribute. A state that facilitates and encourages ethical conduct among its citizens in a pandemic can build public trust and supportive capacity that will endure beyond the second wave of COVID-19 that certainly awaits us all.

Availability of Data and Material NA

Code Availability NA

Authors' Contributions All authors were equally involved in the study conceptualization and design, investigation, analysis, reflection, manuscript writing, and review. KAS conducted the administrative work for journal submission. All authors have read and approved the manuscript and accept responsibility for the content.

\section{Compliance with Ethical Standards}

Conflict of Interest All authors declare that they have no conflicts of interest.

Ethics Approval NA

Consent to Participate NA

Consent for Publication NA 


\section{References}

Agamben, Giorgio. 2020. The state of exception provoked by an unmotivated emergency. Positions Politics, 26 February 2020. http://positionswebsite.org/giorgio-agamben-the-state-of-exception-provoked-by-anunmotivated-emergency/.

Ai, Weiwei, Director. 2020. Coronation. Berlin: AWW Germany. First released on 20 August 2020, via Alamo Drafthouse Cinemas. https://ondemand.drafthouse.com/film/virtual-cinema-coronation/? m utk= 46868ae7b5e214dc4f62a767af9bf4af\&utm_campaign=NAT+2020-08-20+-+Newsletter+Unopened+ Markets\&utm_medium=Email\&utm_source=Newsletter.

Bensimon, Cecile, and Ross E.G. Upshur. 2007. Evidence and effectiveness in decisionmaking for quarantine. American Journal of Public Health 97 (Suppl 1): S44-S48. https://doi.org/10.2105/AJPH.2005.077305.

Bi, Jiaojiao [毕娇娇], and Yinji Piao [朴银姬]. 2020. An analysis of ritual communication in the news reports on COVID-19 [新冠肺炎疫情报道中的仪式传播分析]. Journal of News Research [新闻研究导刊] 11 (15): 67-70.

Cammett, Melanie, and Evan Lieberman. 2020. Building solidarity: challenges, options, and implications for COVID-19 responses. COVID-19 Rapid Response Impact Initiative, White Paper 4. Edmond J. Safra Center for Ethics, 30 March 2020. https:/ethics.harvard.edu/files/center-for-ethics/files/ safrawhitepaper4c.pdf?m=1585845049.

CCTV News [央视新闻]. 2020. 'I only had 3-hour sleep every day lasting for a week' Painful when hearing the broken voice from a Wuhan health worker in an interview! You work hard [“连续一周每天只睡2小时” 听到 武汉医护人员接受采访时沙亚的声音, 好心疼! 辛苦了, 'Lianxu yizhou meitian zhi shui 2 xiaoshi' Tingdao Wuhan yihurenyuan jieshou caifang shi shaya de shengyin, hao xinteng! Xinkule]. TikTok [抖音], 27 January 2020, video, 0:34. https://v.douyin.com/JNBjTnd.

CCTV.com [央视网]. 2020. Hua Zhao, head nurse of the fever clinic, Hankou Hospital, Wuhan asked the nurses not to drink water before entering the isolation area and stay full hours [武汉市汉口医院发热门诊科护 士长赵华为了节省防护服嘱咐护士们进隔离区之前不要喝水, 尽量待足时间, Wuhanshi hankou yiyuan fare menzhenke hushizhang Zhao Hua weile jiesheng fanghufu zhufu hushimen jin geliqu zhiqian buyao heshui, jinliang daizu shijian]. TikTok [抖音], 14 February 2020, video, 0:23. https://v.douyin.com/ JLskkGQ.

Chen, Aria. 2020. Video of female medics in China having their heads shaved sparks backlash over propaganda in the coronavirus fight. New York Times, 14 February 2020. https://time.com/5788592/ weibo-women-coronavirus/. Accessed 9 July 2020.

China.com [中国网]. 2020. Nationally, 3387 HCWs were infected with COVID-19, with over 90\% from Hubei [全国3387名医务人员感染新冠肺炎 超9成来自湖北, Quanguo 3387 ming yiwurenyuan ganran xinguanfeiyan chao 9 cheng laizi hubei]. TikTok [抖音], 24 February 2020, video, 0:05. https://v.douyin.com/J8wk4Mf.

Cover News [封面新闻]. 2020. Early morning scene at designated fever diagnosis and treatment hospital in Wuhan urban area, where citizens lined up in order [凌晨直击武汉市城区发热定点诊疗医院现场, 市民有序排队, Lingchen zhiji wuhanshi chengqu fare dingdian zhenliaoyiyuan xianchang, shimin youyu paidui]. TikTok [抖音], 23 January 2020, video, 0:17. https://v.douyin.com/JLpTVfU.

Cox, Caitríona L. 2020. 'Healthcare heroes': problems with media focus on heroism from healthcare workers during the COVID-19 pandemic. Journal of Medical Ethics 2020 (46): 510-513. https://doi.org/10.1136/ medethics-2020-106398.

Domínguez, Daniela G., Dellanira García, David A. Martínez, and Belinda Hernandez-Arriaga. 2020. Leveraging the power of mutual aid, coalitions, leadership, and advocacy during COVID-19. American Psychologist 75 (7): 909-918. https://doi.org/10.1037/amp0000693.

Dragon TV [东方卫视]. 2020. Painful! The status quo of front line HCWs, to save the protective suits, the solution is wearing diapers and not drinking water! [心疼! 一线医生现状, 为节省防护服, 秘诀竟是不喝水+穿尿 不湿! Xinteng! Yixian yisheng xianzhuang, wei jiesheng fanghufu, mijue jingshi buheshui + chuan niaobushi!]. TikTok [抖音], 31 January 2020, video, 0:56. https://v.douyin.com/JLsjFWL.

Gostin, Lawrence O. 2020. Could - or should - the government impose a mass quarantine on an American city? Health Affairs Blog, 10 March 2020. https:/www.healthaffairs.org/do/10.1377/hblog20200310. 824973/full/.

Gostin, Lawrence O., Eric A. Friedman, and Sarah A. Wetter. Responding to Covid-19: How to navigate a public health emergency legally and ethically. The Hastings Center Report 50 (2): 8-12. https://doi.org/ 10.1002/hast.1090.

Graeber, David, and Andrej Grubačić. 2020a. David Graeber left us a parting gift - his thoughts on Kropotkin's “mutual aid.”. Truthout, 4 September 2020. https://ruthout.org/articles/david-graeber-leftus-a-parting-gift-his-thoughts-on-kropotkins-mutual-aid/. 
Graeber, David, and Andrej Grubačić. 2020b. Introduction. In Mutual Aid: An Illuminated Factor of Evolution. Oakland, CA: PM Press/Kairos, forthcoming.

Herzberg, Frederick, Bernard Mausner, and Barbara B. Snyderman. 1959. The motivation to work. New York, NY: John Wiley.

Hubei Daily [湖北日报]. 2020. We can feel how exhausted she was outside the screen. How can we not feel painful for her [隔着屏幕都能感觉到她的疲急, 谁家的女儿不心疼啊! Gezhe pingmu dou neng ganjuedao tade pibei, shuijia de nver bu xinteng a!]. TikTok [抖音], 15 February 2020, video, 0:06. https://v.douyin.com/ JNBPeV1.

Hubei News [湖北新闻]. 2020. Hugging ice cubes to cool down, with commitment in the summer days. You make the world perfect [抱冰取凉, 夏日的坚守, 这世界有你们才更完美! Bao bing qu liang, xiari de jianshou, zhe shijie you nimen cai wanmei]. TikTok [抖音], 12 March 2020, video, 0:13. https://v.douyin.com/ JLsMhTq.

Hubei Provincial People's Government [湖北省人民政府]. 2020. Announcement by the Wuhan Novel Coronavirus Infection Prevention and Control Headquarters [武汉市新型冠状病毒感染的肺炎疫情防控指挥 部通告(第1号), Wuhan shi xinxing guanzhaung bingdu ganran de feiyan yiqing fangkong zhihuibu tonggao (di 1 hao)]. 23 January 2020. http://www.hubei.gov.cn/zhuanti/2020/gzxxgzbd/zxtb/202001/ t20200123_2014402.shtml.

Hubei TV [湖北卫视]. 2020. Updated! Starting from 0 o'clock on 26 Jan, all fever clinics in Wuhan hospitals are available 24 hours for diagnosis and treatment [最新消息! 26日零时起,武汉所有医院发热门诊24小时接诊, Zuixin xiaoxin! 26 ri lingshi qi,wuhan suoyou yiyuan faremenzhen 24 xiaoshi jiezhen]. TikTok [抖音], 25 January 2020, video, 0:25. https://v.douyin.com/JLpXvAy.

Jiang, Chengxue [姜承雪]. 2020. Real living diary of a Wuhan native in the epidemic [疫情之下, 一个武汉人的真 实生活日记, Yiqing zhixia, yige Wuhan ren de zhenshi shenghuo riji]. WeChat [微信], 8 February 2020. https://mp.weixin.qq.com/s/Pjz_1oP_OaJnZsXcKFLPyw. Accessed 9 July 2020.

Jiang, Jie [姜洁], Yongqing Yuan [袁永庆], Xue Bai [白雪], Kaike Li [李锴科], Jiajie Yu [喻佳洁], and Youping Li [李幼平]. 2020. A study on Concern and Love System building for hospital staff in coronavirus disease 2019 [新冠肺炎防控中一线医务人员关爱体系建设研究]. Medicine and Philosophy [医学与哲学] 41 (15): 6671.

Jiangxi TV [江西卫视]. 2020. Painful when thinking of the HCWs getting wet thoroughly after taking off the protective suits! [想到医护人员脱下防护服后浑身湿透的样子真让人心疼! Xiangdao yihurenyuan tuoxia fanghufu hou hunshen shitou de Yangzi zhen rangren xinteng!]. TikTok [抖音], 5 February 2020, video, 0:18. https://v.douyin.com/JLsUhWq.

Joe W. 2020. Cutting off hair, they are ready to go! [剪去秀发,她们整装出征! Jianqu xiufa, tamen zhengzhuang chuzheng!]. YouTube, 17 February 2020, video, 1:00. https://www.youtube.com/watch?v= WYLW2i4w73E.

Kropotkin, Peter. (1902) 2006. Mutual aid: a factor or evolution. Mineola, NY: Dover Publications.

Liu, Qing [柳青]. 2020. National Health Commission of the People's Republic of China: Near $70 \%$ of volunteer HCWs assisting Wuhan were nurses, with near 90\% were female [国家卫健委: 援鄂医务人员中 护士近70\% 女护士占9成, Guojia weijianwei: yuane yiwurenyuan Zhong hushi jin $70 \%$ nvhushi zhan 9 cheng]. The Cover [封面], 7 April 2020. http://www.thecover.cn/news/3981003. Accessed 9 July 2020.

Liu, Yiqin [刘以秦], Xin Na [信娜], Wang Xiao [王小], Fang Gongyiliu [房宫一柳], Li Shiyun [黎诗韵], Yu Qin [俞琴], Wang Lina [王丽娜], Wang Jingyi [王静仪], Chen Liang [陈亮], Li Siyang [李斯洋], Li Xiyin [李晳 寅], and Li Xingjun [李星郡]. 2020. Saving Wuhan: recording the most difficult three weeks after the lockdown [拯救武汉: 实录封城后最艰难的三周, Zhengjiu Wuhan: Shilu fengcheng hou zui jiannan de sanzhou]. Caijing [财经], 17 February 2020. https://news.caijingmobile.com/article/detail/412418? source id $=40$.

Malm, Heidi, Thomas May, Leslie Francis, Saad Omer, Daniel Salmon, and Robert Hood. 2008. Ethics, pandemics and the duty to treat. American Journal of Bioethics 8 (8): 4-19. https://doi.org/10.1080/ 15265160802317974.

Maslow, Abraham H. (1954) 1979. Motivation and Personality. New York, NY: Harper \& Row.

Molm, Linda D., Jessica L. Collett, and David R. Schaefer. 2007. Building Solidarity through Generalized Exchange: A Theory of Reciprocity. American Journal of Sociology 113 (1): 205-242. https://doi.org/10. 1086/517900:/doi/abs/10.1086/517900.

People.cn [人民网]. 2020. Tears with pain when seeing the faces behind masks! The top searches today belong to you [裉下口罩那一刻瞬间心疼哭了! 今天的热搜, 属于你们! Tuixia kouzhao nayike shunjian xinteng kule! Jintian de resou, shuyu nimen!]. TikTok [抖音], 30 January 2020, video, 0:10. https://v.douyin.com/ JLsfG1M.

People's Daily+ [人民日报+]. 2020. The scene that she took off the sweating-wet protective suit looks like taking off the heavy rain coat on rainy days. You hard work! [当瘦小的她脱下汗水浸湿的防护服, 就像雨天脱 
下厚重的雨衣, 辛苦了! Dang shouxiao de ta tuoxia hanshui jinshi de fanghufu, jiuxiang yutian tuoxia houzhong de yuyi, xinkule!]. TikTok [抖音], 12 March 2020, video, 0:34. https://v.douyin.com/JNBPoC8.

PLA Navy [人民海军]. 2020. To cool down, Ruxia Sun, nurse from Huoshenshan Hospital, is hugging an ice cube pretending eating ice cream [为了让自己快速降温消暑, 火神山护士孙如霞抱着冰块, 假装在吃冰淇淋, Weile rang ziji kuaisu jiangwen xiaoshu, huoshenshan hushi Sun Ruxia baozhe bingkuai, jiazhuang zai chi bingqilin]. TikTok [抖音], 24 March 2020, video, 0:14. https://v.douyin.com/JLs15ya.

Qingfengxia [青蜂侠, The Green Hornet]. 2020. Wenhong Zhang: The front line HCWs worked over 16 hours every day and called for less overtime work after the outbreak [张文宏: 一线医护人员每天工作 16 小时以上 希 望疫情结束后少加班, Zhang Wenhong: yixian yihurenyuan meitian gongzuo 16 xiaoshi yishang xiwang yiqing jieshuhou shao jiaban]. Sina [新浪], 22 February 2020. https://video.sina.cn/news/2020-02-23/ detail-iimxxstf3663211.d.html.

Rothenbuhler, Eric W. 1998. Ritual communication: from everyday conversation to mediated ceremony. Thousand Oaks, CA: Sage Publications.

Rothstein, Mark A. 2015. SARS to Ebola: legal and ethical considerations for modern quarantine. Indiana Health Law Review 12 (1): 227-280. https://doi.org/10.2139/ssrn.2499701.

Spade, Dean. 2020. Solidarity not charity: mutual aid for mobilization and survival. Social Text 14238 (1): 131-151. https://doi.org/10.1215/01642472-7971139.

Springer, Simon. 2020. Caring geographies: The COVID-19 interregnum and a return to mutual aid. Dialogues in Human Geography 10 (2): 112-115. https://doi.org/10.1177/2043820620931277.

Tolbert, Makshya Lenia. 2020. "Checking in with your people": food, mutual aid, black feminism, and COVID-19. Gastronomica 20 (3): 64-65. https://doi.org/10.1525/gfc.2020.20.3.64.

Tsu, Andrew Yu Yue. 1912. The Spirit of Chinese Philanthropy: A Study in Mutual aid. New York, NY: Book on Demand Ltd.

Upshur, Ross E.G. 2003. The ethics of quarantine. AMA Journal of Ethics 5 (11): 393-395. https://doi.org/10. 1001/virtualmentor.2003.5.11.msoc1-0311.

Wang, Chun [王春], and Li Peng [彭莉]. 2020. Gansu Provincial Maternity and Child-care Hospital responded to the haircut of nurses: no coercion, to prevent infection, easy to wash [甘肃省妇幼保健院回应护士被剃光头: 未强迫,防止感染,方便清洗, Gansusheng fuyou baojianyuan huiying hushi bei tiguangtou: weiqiangpo, fangzhi ganran, fangbianqingxi]. Red Star News [红星新闻], 18 February 2020. https://static.cdsb.com/ micropub/Articles/202002/6e29553f353d1ede7a52784ec096ef34.html.

WeVideo [新京报我们视频]. 2020. Front line HCWs assisting Hubei responded to cutting hair bald: no coercion, for infection prevention 援鄂一线医务回应被剃光头:不会强制 是防止感染, Yuane Yixian yihu huiying bei tiguangtou: buhui qiangzhi shi fangzhi ganran]. Sina Weibo [新浪微博], 19 February 2020. https://m.weibo.cn/6124642021/4473687266722253.

Wynia, Matthew K. 2007. Ethics and public health emergencies: restrictions on liberty. American Journal of Bioethics 7 (2): 1-5. https://doi.org/10.1080/15265160701193559.

Xiao Hang [小杭]. 2020. Real diaries of a girl living in Wuhan [一个武汉女生的真实日记, Yige Wuhan nvsheng de zhenshi riji]. Medium, 9 February 2020. https://medium.com/coronavirus19/\%E8\%B1\%86\%E7\%93\% A3-\%E4\%B8\%80\%E4\%B8\%AA\%E6\%AD\%A6\%E6\%B1\%89\%E5\%A5\%B3\%Е7\%94\%9F\%E7\% 9A\%84\%E7\%9C\%9F\%E5\%AE\%9E\%E6\%97\%A5\%E8\%AE\%B0-e8ff02a7bb8b.

Zeng, Jinyan, and Shaohua Liu. 2020. Epidemic control in China: a conversation with Liu Shao-hua. Made in China Journal 5 (1): 65-77 https://madeinchinajournal.com/2020/02/22/epidemic-control-in-china-aconversation-with-liu-shao-hua/.

Zhang, Xinyan [张新燕]. 2020. The most handsome bald! The male nurses assisting Wuhan cut off their hair to show commitment [最帅光头! 援汉男护士理发明志, Zui shuai guangtou! Yuanhan nanhushi lifa mingzhi]. The Paper [澎艇], 9 February 2020. https://www.thepaper.cn/newsDetail_forward_5878299.

Zhao, Ming [赵明]. 2020. To reduce the risk of infection, male nurses from Guangdong medical team line up for hair cutting: no hair grown before disease controlled [为降低感染几率, 广东医疗队男医护排队剃光头:疫情 不除头发不留, Wei jiangdi ganran jilv, Guangdong yiliaodui nanyihu paidui tiguangtou: yiqing buchu toufa buliu]. Southern Metropolis Daily [南方都市报], 10 February 2020. http://news.southcn.com/nfplus/ nfsp/content/2020-02/10/content_190280555.htm.

Zhizhu Hou Mianbao [蜘蛛猴面包]. 2020a. Wuhan quarantine diary [武汉封城日记, Wuhan fengcheng riji]. Youtube, 2 June 2020, series of 22 videos. https:/www.youtube.com/playlist?list=PLhddqgmqzoydlLOfuQYFHhziVgAeohbP.

Zhizhu Hou Mianbao [蜘蛛猴面包]. 2020b. Wuhan quarantine diary 3 - pet assistance and hotels assisting hospitals [武汉封城日记 3 - 宠物救助及酒店协助医院, Wuhan fengcheng riji 3 - Chongwu jiuzhu ji jiudian xiezhu yiyuan]. Youtube, 28 January 2020, video, 12:07. https://www.youtube.com/watch?v= BlC763ft8Ss\&list=PLhddqgmqzoy-dlLOfuQYFHhziVgAeohbP\&index=4\&t=16s. 
Zhizhu Hou Mianbao [蜘蛛猴面包]. 2020c. Wuhan quarantine diary 5 - the society is acting. volunteers are acting [武汉封城日记 5 - 社会在行动, 志愿者在行动, Wuhan fengcheng riji 5 - Shehui zai xingdong, zhiyuanzhe zai xingdong]. Youtube, 29 January 2020, video, 4:42. https://www.youtube.com/watch?v= jNwkcjolirY\&list=PLhddqgmqzoy-dlLOfuQYFHhziVgAeohbP\&index=5.

Zhizhu Hou Mianbao [蜘蛛猴面包]. 2020d. Wuhan lockdown 6 - Visiting community services, voluntary meal delivery, visiting old friends [武汉封城日记 6 - 探访社区宣传服务, 义务送餐, 拜访独居老友, Wuhan fengcheng riji 6 - Tanfang shequ xuanchuan fuwu, yiwu songcan, baifang duju laoyou]. Youtube, 4 February 2020, video, 8:58. https://www.youtube.com/watch?v=7RRNWDJDMeM\&list=PLhddqgmqzoydlLOfuQYFHhziVgAeohbP\&index=6.

Zhizhu Hou Mianbao [蜘蛛猴面包]. 2020e. Wuhan quarantine diary 15 - drifters in the underground [武汉封城 日记 15 - 地下通道流浪者, Wuhan fengcheng riji 15 - Dixia tongdao liulangzhe]. Youtube, 6 March 2020, video, 13:08. https://www.youtube.com/watch?v=7RRNWDJDMeM\&list=PLhddqgmqzoydlLOfuQYFHhziVgAeohbP\&index=6.

Zhizhu Hou Mianbao [蜘蛛猴面包]. 2020f. Wuhan quarantine diary 15+ - Donating to those left in Wuhan [武 汉封城日记15+ - 捐助滞留人员, Wuhan fengcheng riji 15+ - Juanzhu zhiliu renyuan]. Youtube, 14 March 2020, video, 11:05. https://www.youtube.com/watch?v=2GRnSVyDL7A\&t=98s.

Zhizhu Hou Mianbao [蜘蛛猴面包]. 2020g. Wuhan quarantine diary 18 - Wuhan volunteers [武汉封城日记 - 18 武汉志愿者, Wuhan fengcheng riji 18 - Wuhanzhiyuanzhe]. Youtube, 23 March 2020, video, 23:14. https:// www.youtube.com/watch? $=\mathrm{jV} 3 \mathrm{rKra} P W A \& l i s t=P L h d d q g m q z o y d l L O f u Q Y F H h z i V g A e o h b P \& i n d e x=$ 17.

Zhizhu Hou Mianbao [蜘蛛猴面包]. 2020h. Wuhan quarantine diary 4 - the construction site of Leishenshan and the empty city in the dark [武汉封城日记 4 - 雷神山医院建设工地与夜里的空城, Wuhan Fengcheng Riji 4 - leishenshan yiyuan jianshe gongdi yu yeli de kongcheng]. Bilibili [㗪哩呰哩动画], 31 January 2020, video, 3:54. https://www.bilibili.com/video/BV1r7411B7EK.

Zhizhu, and Yanping Ni. 2020. Special: Interview with ZHIZHU (Wuhan Mutual Aid Practitioner and Vlogger). In Revaluing Care in the Times of Covid-19, podcast series by Duke Gender, Sexuality, and Feminist Studies (Duke GSF). Anchor, 25 August 2020. https://anchor.fm/duke-gsf/episodes/SpecialInterviewwith-ZHIZHU-Wuhan-Mutual-Aid-Practitioner-and-Vlogger-ei9oo3. Accessed 26 September 2020 .

Publisher's Note Springer Nature remains neutral with regard to jurisdictional claims in published maps and institutional affiliations. 